\title{
Markov-switching models and the unit root hypothesis in real U.S. GDP
}

\author{
Maximo Camacho* \\ Universidad de Murcia \\ mcamacho@um.es
}

\begin{abstract}
In this paper, I find that real U.S. GDP is better characterized as a trend stationary Markov-switching process than as having a (regime-dependent) unit root. I examine the effects of both assumptions on the analysis of business cycle features and their implications for the persistence of the dynamic response of output to a random disturbance.
\end{abstract}

JEL Classification: E32, C22, E27.

Keywords: Business Cycles, Output Growth, Time Series.

\footnotetext{
* Errors are my own responsibility. The author thanks the financial support of MICINN (ECO201019830) and Fundación Séneca (11998/PHCS/09). Software (written in GAUSS) used in this paper can be obtained from the author's web page.

M. Camacho, Departamento de Métodos Cuantitativos para la Economía y la Empresa. Facultad de Economía y Empresa. Campus de Espinardo, 30100 Universidad de Murcia, Spain. Phone: +34 968 367982 Fax: +34 968367905 .
} 


\section{Introduction}

Since the influential work of Hamilton (1989) many authors have used Markovswitching models to capture the business cycle regime shifts in US output. In his seminal specification, apart from the unit root in the permanent component which exhibits the Markov switching dynamics, the model also restricts one of the roots of the autoregressive process to unity. Although some extensions of this model have been proposed in the related literature, such as Lam (1990) who relaxes the unit root assumption in the cyclical component, and Kim and Nelson (1999) who assume that the business cycle affects the transitory component, they still model the permanent component of the series as having a unit root. Rather than testing, the vast majority of empirical researches assume that the logarithm of output follows a random walk with drift whose stationary differences evolve according to an autoregressive Markovswitching process. ${ }^{1}$

Reinforcing these practical analyses, it is worth recalling that the standard Augmented Dickey-Fuller (ADF) tests unequivocally signal that the log of postwar US quarterly output contains a unit root. However, motivated by the low power of ADF tests in economically relevant trend-stationary alternatives, several authors cast some doubts about the unit root hypothesis. Diebold and Senhadji (1996) conducted ADF tests to several long spans of annual real GNP data and conclude that the autoregressive root of output is close to but less than unity. Lumsdaine and Papell (1997) applied unit root tests against endogenously determined structural breaks to reject the stochastic trend hypothesis in favor of a deterministic trend with breaks.

Following Hall, Psaradakis and Sola (1999), I employ a regime-switching extension of the Augmented Dickey-Fuller (ADF) test to provide further evidence on the uncertain unit root in quarterly US real GDP. ${ }^{2}$ My results confirm with strong support that a trend stationary Markov-switching process describes all the characteristics of US business cycles better than in the case of assuming that the trend is (regime-dependent) stochastic.

\section{Markov-switching unit root tests}

Let $y_{t}$ be (100 times) the log of quarterly US real GDP. The Markov-switching unit root test used in this paper can be obtained by running the regression of the ADF test where the constant term is driven by an unobservable state variable $s_{t}$ :

$$
\Delta y_{t}=\rho y_{t-1}+c_{s_{t}}+b t+\sum_{j=1}^{k} \gamma_{j} \Delta y_{t-j}+\varepsilon_{t},
$$

where $\varepsilon_{t} \sim i i N(0, \sigma)$. The state variable is assumed to evolve according to an irreducible 2-state Markov chain whose transition probabilities are defined by

\footnotetext{
${ }^{1}$ Clements and Krolzig (2004), Kim, Morley and Piger (2005), Chauvet and Hamilton (2006), and Camacho and Perez Quiros (2007) are significant recent examples which do not apply unit root tests.

${ }^{2}$ Markov-switching unit root tests have recently been applied to current accounts (Raybaudi, Sola and Spagnolo, 2005), exchange rates (Kanas and Genius, 2005), and stock prices (Chen, 2008).
} 


$$
p\left(s_{t}=j / s_{t-1}=i, s_{t-2}=h, \ldots, \Omega_{t-1}\right)=p\left(s_{t}=j / s_{t-1}=i\right)=p_{i j}
$$

where $i, j=0,1$, and $\Omega_{t}$ refer to the information set up to period $t .^{3}$ In short, this model endogenously permits the constant term of the time series to switch as the date and regime changes.

The unit root tests are based on the $t$-statistic, $t_{\rho}$, associated with $\rho=0$. The $t$ statistic can be easily computed as a ratio of the estimated parameter and its standard deviation which can be obtained from the negative of the Hessian of the log-likelihood function evaluated at the optimum. However, its distribution under the null is non standard. Hall et al. (1999) calculate the empirical $p$-values of this test by simulating the model under the null. The steps of the simulations are the following. First, save the maximum likelihood parameter estimates and the residuals of the model under the null. Second, generate a relatively large number $B$ of disturbances with sample size equals to that of the data generating process by bootstrapping the residuals. ${ }^{4}$ Third, generate a dichotomous state variable by using the estimated transition probabilities. Fourth, use the disturbances and the estimated parameters to generate realizations of $y_{t}$. Fifth, fit expression (1) to each realization and compute a set of $B$ simulated $t$-statistics. The $p$ value of the unit root test is the percentage of the generated $t$-ratios that are below $t_{\rho}$.

\section{Empirical analysis}

Figure 1 plots the logarithms of postwar quarterly US real GDP (downloaded from Federal Reserve Bank of St. Louis) from 1947.1 to 2009.4. The dynamics of the time series exhibits the two familiar growth and cycle features of output. Although output displays a clear upward trend, the positively trended behavior is sometimes interrupted by broad changes of direction that seem to mark quite well the NBERreferenced business cycles which are plotted as shaded areas.

Figure 1. (log of) US Gross Domestic Product 1947.1-2009.4

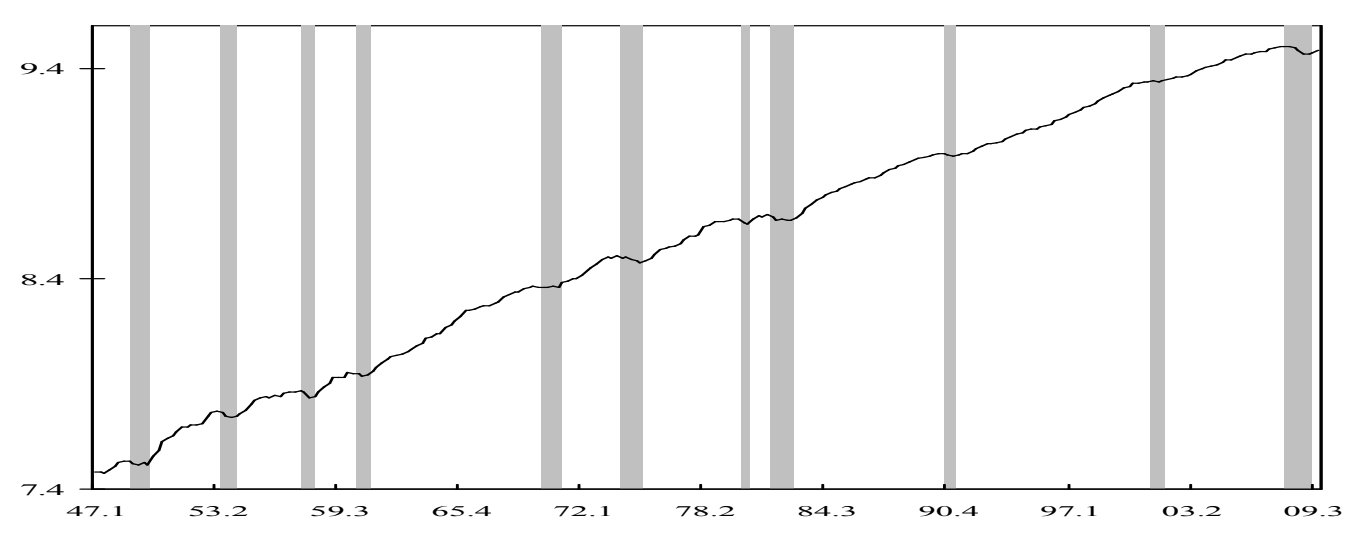

Notes. Shaded areas refer to NBER recessions.

\footnotetext{
${ }^{3}$ Readers interested in model's estimation are referred to Hamilton (1989).

${ }^{4}$ Kanas and Genius (2005) generate the disturbances from a $N(0, \hat{\sigma})$. In the empirical application we followed both procedures with similar results.
} 
These two features are also appreciated in US output growth. Figure 2 shows that while output growth fluctuates around its positive sample mean, there are episodes of lower and even negative growth that coincide with NBER recessions. Since the work by Hamilton (1989), it has been generally accepted that the business cycle dynamics of output can be appropriately modeled by using an unobserved Markov-switching process.

Figure 2. (growth rate) US Gross Domestic Product 1947.1-2009.4

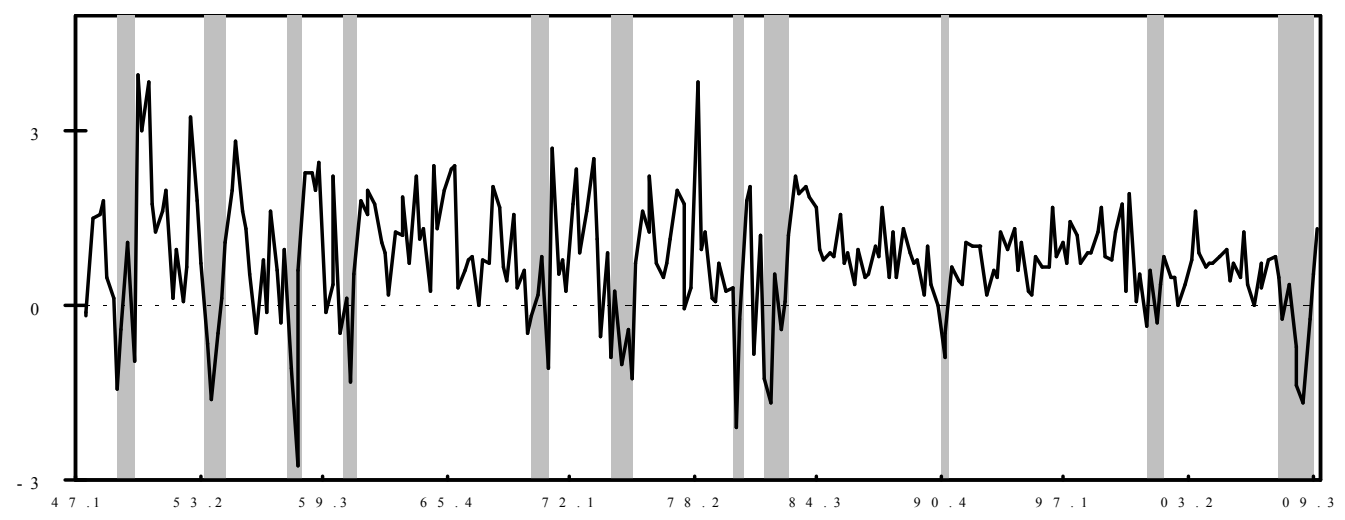

Notes. Shaded areas refer to NBER recessions.

In this paper, I concentrate on whether the positive but cycle-dependent trend exhibited by output is either deterministic or stochastic which has dramatically different implications on whether or not macroeconomic shocks persist. In the trend-stationary Markov-switching case, output is viewed as a time series that cannot exceed a ceiling level but that it is occasionally plucked downward by recessions which have only temporary effects. On the contrary, when output is characterized as having a (regimedependent) unit root, recessions are viewed as having permanent effects on the level of production. Let me examine the implications of these two alternative specifications in terms of both business cycle characteristics and persistence of shocks.

On the one hand, the representation of output as a trend stationary Markovswitching process leads to the following estimates (standard errors are in parentheses):

$$
y_{t}=\underset{(9.10)}{37.45} s_{t}+\underset{(9.08)}{35.71}\left(1-s_{t}\right)+\underset{(0.10)}{0.34 t}+\underset{(0.01)}{0.95} y_{t-1}
$$

where $\hat{\sigma}=\underset{(0.05)}{0.54}, \hat{p}_{00}=\underset{(0.02)}{0.94}$, and $\hat{p}_{11}=\underset{(0.08)}{0.73}$. To assert the accuracy of the model to account for the U.S. business cycles, Figure 3 displays the estimated smoothed probabilities of state 1 . According to the reasonable matching between the quarters of high probabilities of state 1 and the NBER recessions, it is easy to interpret state 1 as recession and the series plotted in this chart as probabilities of being in recession. ${ }^{5}$ The probabilities are close to either zero or one, suggesting that the model is capturing well the underlying pattern of the dichotomous shifts between expansions and recessions.

\footnotetext{
${ }^{5}$ Probably because it was very mild in terms of output, the only exception is the 2001 recession.
} 
Figure 3. Smoothed recession probabilities from $y_{t}=c_{s_{t}}+b t+\chi_{t-1}+\varepsilon_{t}$

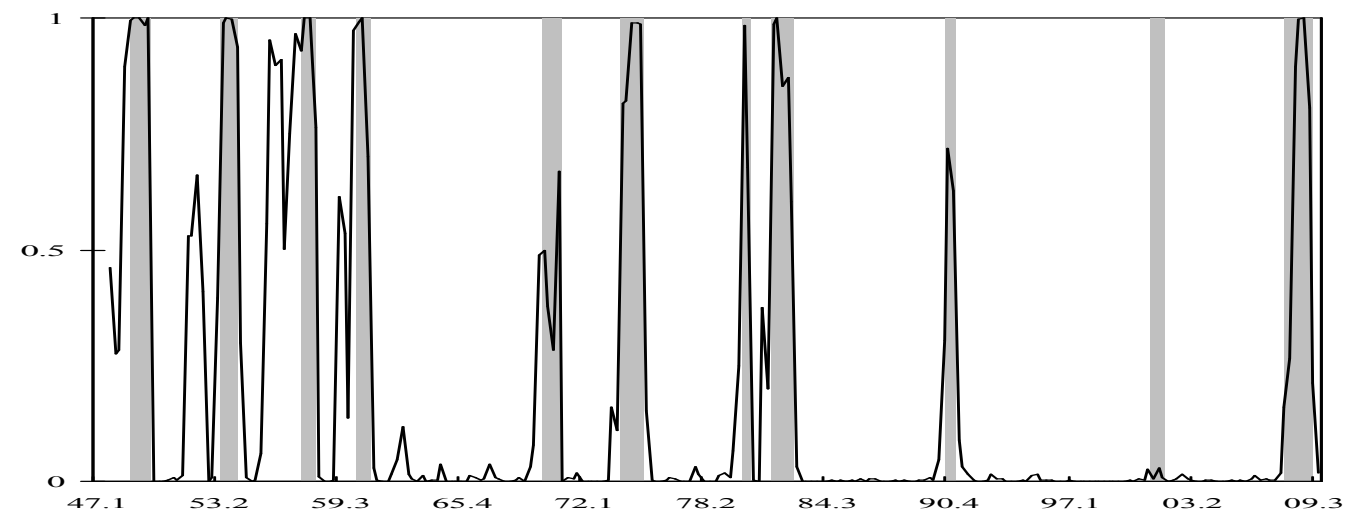

Notes. Shaded areas refer to NBER recessions.

An interesting implication of the Markov-switching framework is that one can derive the expected number of quarters that business cycles prevail. Conditional on being in state $j$, the expected duration of a typical business cycle phase is $\left(1-p_{j j}\right)^{-1}$. This implies that the expected duration of expansions and recessions are about 16.7 and 3.7 quarters, respectively. These estimates are close to the historical average duration of expansions (57 months) and recessions (10 months) according to the NBER figures.

On the other hand, under the assumption of unit root I estimate the following difference stationary Markov-switching process:

$$
\Delta y_{t}=\underset{(0.12)}{0.67} s_{t}-\underset{(0.54)}{0.92}\left(1-s_{t}\right)+\underset{(0.54)}{0.30 \Delta y_{t-1}}
$$

where $\hat{\sigma}=\underset{(0.07)}{0.69}, \hat{p}_{00}=\underset{(0.05)}{0.95}$, and $\hat{p}_{11}=\underset{(0.25)}{0.33}$. Figure 4 reveals that quarters of high probabilities of state 1 also agree with the NBER recessions although the ability to differentiate between expansions and recessions diminishes considerably. In five out of eleven recessions, the probabilities are never higher than 0.5 and the recessions of 1970 , 1991 and 2001 are clearly missed. In addition, the agreement of the parameter estimates with the NBER business cycles dates deteriorates significantly. The expected duration of expansions agrees with the figures suggested by the NBER. However, recessions, which are expected to last 1.5 quarters, are much less persistent than the NBER figures.

Figure 4. Smoothed recession probabilities from $\Delta y_{t}=c_{s_{t}}+\gamma \Delta y_{t-1}+\varepsilon_{t}$

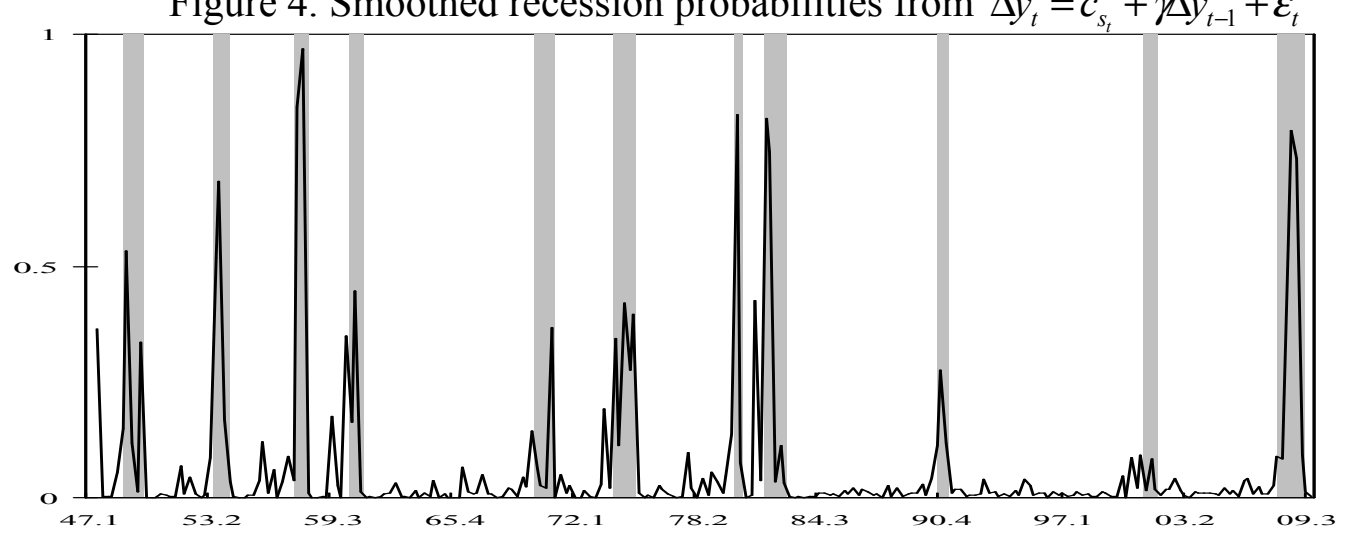

Notes. Shaded areas refer to NBER recessions. 
Apart from the different accuracy of trend stationary versus difference stationary Markov-switching specifications on business cycle description, these models have very different implications for the persistence of the dynamic response of output to a random shock. Although computing impulse responses in nonlinear contexts is not trivial, one can perform a simple exercise to examine the different responses of output which are computed from models (3) and (4). Let me assume that the economy is in state $s_{t}=0$ at the date of the shock and that it remains in this state during the computation period of the responses. For various horizons $h$, Figure 5 shows the effects of a unit shock in period $t$ on $y_{t+h}$ that are estimated from both models. In the difference stationary process, the effect of an innovation is magnified and persistent and the transmission to output is quick. The shock eventually increases output by about one and a half times the size of the innovation, it has long term effects on output, and the complete effect on output is reached after about one year. By contrast, the long term effect advocated by the trend stationary process is progressively eliminated as reversion to the trend dominates. However, these effects do not become negligible until about ten years after the shock.

Figure 5. Responses to an unexpected unit shook

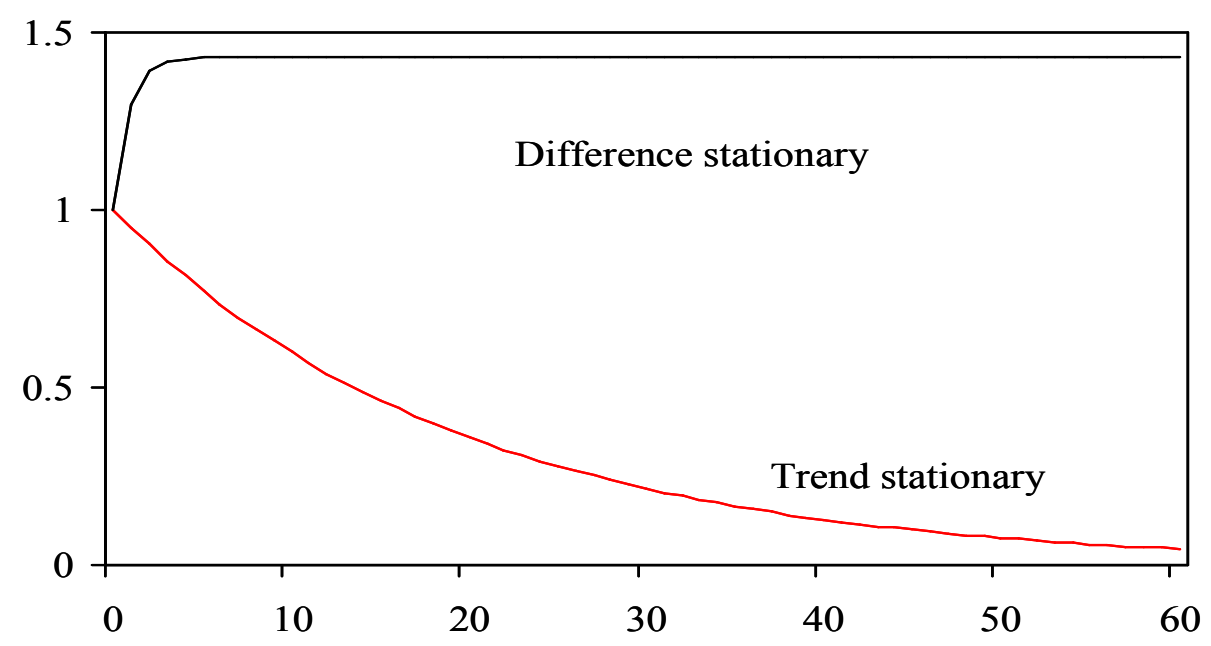

Notes. The horizons of the responses (x-axis) are measured in quarters.

Because the trend stationary and the difference stationary Markov-switching processes have different cyclical behavior and dynamic responses, it would be useful to apply a test capable to distinguish between them. Prior to modeling output growth as a Markov-switching autoregressive process, ADF-type unit root tests are often used to validate that the series of output contains a unit root. To apply this test to (log of) output, I estimate expression (1) by imposing that the constant term is not regimedependent. To specify the number of lagged difference terms, I use Akaike, Schwarz, and Hannan-Quinn criteria which unequivocally select $k=1 .^{6}$ The ADF statistic value is -2.20 and the associated one-sided $p$-value (using MacKinnon, 1996) is 0.49. Notice then that the null of unit root is not rejected at conventional test sizes.

Although using linear unit root tests to examine whether (log of) output contains a unit root is quite extended in the empirical literature, the validity of these results in the presence of Markov-switching nonlinearities has recently been questioned. In a recent contribution, Nelson, Piger and Zivot (2001) show that standard unit root tests do a poor

\footnotetext{
${ }^{6}$ I also checked that residuals were serially uncorrelated.
} 
job on distinguishing trend stationary Markov-switching processes from integrated time series.

To overcome this drawback, Hall et al. (1999) generalize the ADF testing strategy to allow for Markov-switching dynamics in the structure of the time series. As summarized in Section 2, the strategy consists on the following steps. First, the authors propose to compute the $t$-statistic associated with the null $\rho=0$ in expression (1) as the ratio of the estimated parameter and its standard deviation. In the case of (log of) US output, the estimated statistics is $t_{\rho}=-4.20$. Second, they propose a method to simulate the distribution of the statistics under the null of trend stationary Markov switching. To compute the $p$-value associated with the unit-root null, the model is simulated 10,000 times under the null, expression (1) is estimated in each of these simulations, and the $t$ ratios of the null $\rho=0$ are computed. The proportion of the replications in which the generated $t$-ratios are below $t_{\rho}$ is 0.007 when simulations are computed by bootstrapping the residuals and it is 0.005 when they are computed from Monte Carlo simulation. Accordingly, the null of (regime dependent) unit root is then overwhelmingly rejected against the alternative that output is a trend stationary Markovswitching process at standard test sizes.

\section{Conclusion}

The question of deterministic versus stochastic trend in US GDP has been the source of an intense debate in the last three decades. This paper shows that output is better characterized by a trend stationary rather than by a difference stationary Markovswitching process. In addition, the paper shows that the Markov-switching trend stationary specification leads to business cycle properties which are in closer agreement with those proposed by the NBER than the Markov-switching unit root specification.

As in the context of linear models, relaxing the unit root hypothesis in Markovswitching specifications has important implications on the persistence effects of innovations. Under the unit root Markov-switching specification, recessions are viewed as having large permanent effects on the level of output. On the contrary, the Markovswitching trend stationary specification constrains the effects of recessionary shocks to be transitory.

\section{References}

Camacho, M., and Perez Quiros, G. 2007. Jump-and-rest effect of US business cycles. Studies in Nonlinear Dynamics and Econometrics 11 (4): Art 3.

Chauvet, M., and Hamilton, J. 2006. Dating business cycle turning points in real time. In Nonlinear Time Series Analysis of Business Cycles, eds. C. Milas, P. Rothman, and D. Van Dijk, Amsterdam: Elsevier Science, pp. 1-54.

Chen, S. 2008. Non-stationarity and Non-linearity in stock prices: Evidence from the OECD countries. Economics Bulletin 11 (3): 1-11.

Clements, M., and Krolzig, H-M. 2003. Business cycle asymmetries: characterization and testing based on Markov-switching autoregressions. Journal of Business and Economic Statistics 21: 196-211.

Hall, S., Psaradakis, Z., and M. Sola, M. 1999. Detecting periodically collapsing bubbles: A Markov-switching unit root test. Journal of Applied Econometrics 14: 143154. 
Hamilton, J. 1989. A new approach to the economic analysis of nonstationary time series and the business cycles, Econometrica 57: 357-384.

Kanas, A., and Genius, M. 2005. Regime (non)stationarity in the US/UK real exchange rate. Economics Letters 87: 407-413.

Kim, Ch., Nelson, Ch. 1999. Friedman's plucking model of business fluctuations: tests and estimates of permanent and transitory components. Journal of Money, Credit, and Banking 31: 317-334.

Kim, Ch., Morley, J., and Piger, J. 2005. Nonlinearity and the permanent effects of recessions. Journal of Applied Econometrics 20: 291-309.

Lam, P. 1990. The Hamilton model with a general autoregressive component. Journal of Monetary Economics 26: 409-432.

Lumsdaine, R., and Papell, D. 1997. Multiple trend breaks and the unit-root hypothesis. The Review of Economics and Statistics 79: 212-218.

MacKinnon, J. 1996. Numerical distribution functions for unit root and cointegration tests. Journal of Applied Econometrics 11: 601-618.

Nelson, Ch., Piger, J., and Zivot, E. 2001. Markov regime switching and unitroot tests. Journal of Business and Economic Statistics 19: 404-415.

Raybaudi, M., Sola, M., Spagnolo, F. 2004. Red signals: Current account deficits and sustainability. Economics Letters 84: 217-223. 